Article

\title{
Spatial-Temporal Variations in Atmospheric Factors Contribute to SARS-CoV-2 Outbreak
}

\author{
Raffaele Fronza ${ }^{1}$, Marina Lusic ${ }^{2,3} \mathbb{D}$, Manfred Schmidt ${ }^{1}$ and Bojana Lucic ${ }^{2,3, * \mathbb{D}}$ \\ 1 Biocomputing Unit, Genewerk GmbH, 69120 Heidelberg, Germany; \\ raffaele.fronza@genewerk.de (R.F.); manfred.schmidt@genewerk.de (M.S.) \\ 2 Department of Infectious Diseases, Integrative Virology, Heidelberg University Hospital, \\ 69120 Heidelberg, Germany; marina.lusic@med.uni-heidelberg.de \\ 3 German Center for Infection Research, Partner Site Heidelberg, 69120 Heidelberg, Germany \\ * Correspondence: bojana.lucic@med.uni-heidelberg.de
}

Received: 27 April 2020; Accepted: 26 May 2020; Published: 27 May 2020

check for updates

\begin{abstract}
The global outbreak of severe acute respiratory syndrome coronavirus 2 (SARS-CoV-2) infection causing coronavirus disease 2019 (COVID-19) has reached over five million confirmed cases worldwide, and numbers are still growing at a fast rate. Despite the wide outbreak of the infection, a remarkable asymmetry is observed in the number of cases and in the distribution of the severity of the COVID-19 symptoms in patients with respect to the countries/regions. In the early stages of a new pathogen outbreak, it is critical to understand the dynamics of the infection transmission, in order to follow contagion over time and project the epidemiological situation in the near future. While it is possible to reason that observed variation in the number and severity of cases stems from the initial number of infected individuals, the difference in the testing policies and social aspects of community transmissions, the factors that could explain high discrepancy in areas with a similar level of healthcare still remain unknown. Here, we introduce a binary classifier based on an artificial neural network that can help in explaining those differences and that can be used to support the design of containment policies. We found that SARS-CoV-2 infection frequency positively correlates with particulate air pollutants, and specifically with particulate matter $2.5\left(\mathrm{PM}_{2.5}\right)$, while ozone gas is oppositely related with the number of infected individuals. We propose that atmospheric air pollutants could thus serve as surrogate markers to complement the infection outbreak anticipation.
\end{abstract}

Keywords: SARS-CoV-2; infection dynamics; viral outbreak; $\mathrm{PM}_{2.5}$; ozone

\section{Introduction}

The pandemic of the new coronavirus SARS-CoV-2 causing COVID-19 disease is testing the resilience of all the vital components of our communities, and specifically healthcare systems. The majority of new infections are now being reported outside of China, where the outbreak officially originated in December 2019 in Wuhan.

SARS-CoV-2 belongs to a family of Coronaviridae, the common spillover pathogens that have recently caused two viral outbreaks, SARS and the Middle East respiratory syndrome (MERS). As SARS-CoV and MERS-CoV, new SARS-CoV-2 most probably originated from bats, however the intermediate host of the new coronavirus remains unknown to date [1]. Like other coronaviruses, SARS-CoV-2 is a spherical enveloped virus with the positive-sense RNA genome. In general, coronaviruses have a relatively slow viral multiplication rate with the in vitro maximal replication efficiency at $32-33{ }^{\circ} \mathrm{C}$, and a rapid decrease in infectivity at higher temperatures [2]. Moreover, coronaviruses can remain infectious for several days on inert surfaces and in the external environment $[3,4]$. 
The general indicator of transmissibility of a viral infection, basic reproduction number $\left(R_{0}\right)$, which indicates how many secondary infections are caused by a primary infected person, has been estimated for SARS-CoV-2 to be between 2 and 3, mostly using data from China [5]. However, these estimations might not be accurate for what seems to be the faster-spreading European epidemic. The main transmission mode of SARS-CoV-2 is person-to-person contact [6]. Besides physical contact, transmission can occur through physiological aerosol airborne droplets composed mainly of water in the act of breathing, talking, coughing and sneezing [7,8]. The droplets that compose aerosol include various physiological constituents (cells, proteins, salts, small molecules) but also contain exogenous particles, such as viruses [7]. The dimension of these droplets varies, ranging from millimeters to microns, leading to a substantial difference in the detrimental effect in the case of infective particles $[9,10]$. Large droplets have a low probability of passing the upper respiratory tract, whereas the smaller particles have the capacity to reach the bronchi and lungs [7]. It is considered that droplets independent from the dimension, fall promptly to the ground as subordinated to gravity force, explaining the reason for the heuristic rule of maintaining a distance of a few meters to avoid the infection. However, the gravity force is counteracted by Stokes friction and, in the case of particles up to $4 \mu \mathrm{m}$, the two contrasting forces are equilibrating and the particles are floating in the air [11].

Air pollutants $\mathrm{PM}_{2.5}$ and $\mathrm{PM}_{10}$ are atmospheric aerosols that are classified on the basis of the aerodynamic particulate size (i.e., $<2.5$ and $<10 \mu \mathrm{m}$ ). In-depth analysis and re-analysis of large cohort studies around the world showed evidence that both short- and long-term exposure to particulate matter is associated with all-cause and cardiopulmonary mortality (reviewed in [12,13]). General hypothesized pathophysiological mechanisms that link PM exposure to cardiopulmonary diseases involve the rapid progression of existing pulmonary conditions, pulmonary and systemic oxidative stress, inflammation, atherosclerosis and accompanying cardiovascular diseases [14,15]. This is supported by clinical studies showing that air pollution, and specifically particulate matter $\mathrm{PM}_{2.5}$, positively correlates with the number of outpatient and emergency visits and hospitalizations for acute respiratory infections [16,17]. Toxicological studies suggest that $\mathrm{PM}_{2.5}$ are especially harmful as smaller particles are more prone to penetrate deeper into the lungs [18,19]. Strikingly, ultrafine particles ( $<100$ nanometres in diameter) have been also found in the brain, indicating that PM effects are not limited to respiratory and cardiovascular systems [20,21]. Similarly to particulate matter, atmospheric pollutant ozone $\left(\mathrm{O}_{3}\right)$, an oxidant present in the environment, also contributes to the risk of respiratory illness [22]. Furthermore, both $\mathrm{PM}_{2.5}$ and $\mathrm{O}_{3}$ are found among the most prominent environmental cardiovascular risk factors [23]. However, unlike particulate matter, ozone is commonly used as a method for air, water and object disinfection. Indeed, in the case of an airborne influenza virus type A infection, $\mathrm{O}_{3}$ was found to rapidly inactivate the virus and to reduce morbidity in infected mice [24-26].

It is generally recognized that respiratory viruses, such as influenza virus and SARS-CoV, can be transmitted by airborne diffusion of infectious droplets generated by coughing or sneezing via the nuclei of small aerodynamic diameter [27]. We thus hypothesized that airborne transmission of SARS-CoV-2 can be influenced by, but is not limited to, indirect action of certain atmospheric conditions that maintain infectious nuclei suspended for prolonged periods of time, parameters that also act on atmospheric pollutants. In this study, we analyzed particulate matter and ozone ambiental concentration in relation to SARS-CoV-2 infected cases from Italy and three other European countries: France, Germany and Spain. We propose that the same atmospheric conditions that elevate the air concentration of PM and $\mathrm{O}_{3}$ are also contributing to the modulation of the viral outbreak. We provide a qualitative model that predicts the outbreak severity taking into account only a reduced set of atmospheric factors. We propose that (1) atmospheric conditions that elevate the PM concentration are also involved in the SARS-CoV-2 viral outbreak, and that (2) the environmental ozone concentration can be a repressing factor that attenuates SARS-CoV-2 infection. 


\section{Data and Methods}

\subsection{Study Setting and Data}

The hourly concentration $\left(\mu \mathrm{g} / \mathrm{m}^{3}\right)$ of $\mathrm{PM}_{2.5}, \mathrm{PM}_{10}, \mathrm{O}_{3}$ and $\mathrm{NH}_{3}$ in 47 regional capitals of Europe, and 107 major Italian cities, was retrieved in the period from 10th of February 2020 to 10th of April 2020. For the same period, we obtained the hourly temperature $\mathrm{T}\left({ }^{\circ} \mathrm{K}\right)$, the dewpoint temperature TD $\left({ }^{\circ} \mathrm{K}\right)$, the $\mathrm{u}$ and $\mathrm{v}$ speed components of the wind $\left(\mathrm{m} \mathrm{s}^{-1}\right)$, and the surface pressure $\mathrm{P}(\mathrm{Pa})$. For seasonal analysis, the first 30 days of March, June, September, and December were taken from the year 2018. The files are in crib2 or netCDF format retrieved from http://macc-raq-op.meteo.fr/. The concentration of pollutants $\mathrm{PM}_{2.5}, \mathrm{PM}_{10}, \mathrm{O}_{3}$ and $\mathrm{NH}_{3}$ were extracted from the ENSEMBLE multi-model that combines the values of other seven models: CHIMERE METNorway, EMEP RIUUK, EURADIM KNMI/TNO, LOTOS-EUROS SMHI, MATCH FMI, SILAM Météo-France, and MOCAGE UKMET (https://www.regional.atmosphere.copernicus.eu). The climate factors T, TD, wind components and $P$ are obtained from the Copernicus Climate Change Service Climate Data Store CDS [28]. The European domain is defined within the coordinates $-25 \mathrm{E} / 70 \mathrm{~N}$ and $45 \mathrm{E} / 30 \mathrm{~N}$, with 0.1 and 0.28125 degrees of horizontal and vertical resolution, respectively. The values were extracted and processed into a Linux environment using bash scripts, cdo 1.7 .0 and the R packages raster and ncdf4 [29-31].

The geographical center of the province capital corresponds to the geometric center of the quadrant. The latitude and longitude of Italian cities were derived directly from the epidemiological data provided by the Protezione Civile. The latitude and longitude of European cities were obtained manually.

Italian province dataset was subdivided in the three macroregions: north Italian provinces (latitude $\geq 44.85$ ), central Italian provinces (41.5 $\leq$ latitude $\geq 44.85$ ), and south Italian provinces (latitude $\leq 41.5$ ).

To express the overall quantity in the study period for $\mathrm{PM}_{2.5}, \mathrm{PM}_{10}, \mathrm{NH}_{3}$, and $\mathrm{O}_{3}$, we developed and tested two indexes, the average daily maximum (AdM) and the average daily value (AdV). Considering, as an example, the starting day of the atmospheric factors sampling (22nd of February 2020), the incubation period (6 days, [32]) and the day at which we started the survey (25th of March 2020), D was imposed as $D=27$. Considering that there are $L$ geographical areas, and $24 \mathrm{~h}$ a day $(H)$, the $A d M$ at a day $d$ is a vector computed as:

$$
A d M_{l}=\frac{1}{D} \sum_{d=1}^{D} \max _{h}\left(x_{h d l}\right)
$$

where $x_{h d c}$ is the atmospheric air pollution value at hour $h$, day $d$, and location $l$. The $A d V$ is computed as:

$$
A d V_{l}=\frac{1}{D H} \sum_{d=1}^{D} \sum_{h=1}^{H} x_{h d l}
$$

The two indexes are similar with $A d M$ being more sensitive to rapid changes of the factors whereas $A d V$ is more robust to spikes and responses to temporal consistent changes. For ozone, the concentrations were converted from $\mu \mathrm{g} / \mathrm{m}^{3}$ to $\mathrm{ppm}$ assuming standard conditions $(273.1 \mathrm{~K}, 1 \mathrm{~atm})$ and using the relation:

$$
p p m=c \cdot \frac{M V}{M M} \cdot 10^{-3}=0.46710^{-3} \cdot c
$$

where $c$ is the ozone concentration $\left(\mu g / m^{3}\right), M V$ is the molar volume approximated with an ideal gas (22.414 L/mol) and MM is the molar mass (48 g/mol).

The average daily temperatures, $A d T D$ and $A d T$, and the average daily surface pressure $A d P$ are obtained similarly to $A d V$

$$
\operatorname{AdTD}_{l}=\frac{1}{D H} \sum_{d=1}^{D} \sum_{h=1}^{H} t d_{h d l}
$$




$$
\begin{aligned}
& A d T_{l}=\frac{1}{D H} \sum_{d=1}^{D} \sum_{h=1}^{H} t_{h d l} \\
& A d P_{l}=\frac{1}{D H} \sum_{d=1}^{D} \sum_{h=1}^{H} p_{h d l}
\end{aligned}
$$

where $t_{h d l}, t d_{h d l}$, and $p_{h d l}$ are the temperature, the dewpoint temperature, and the surface pressure at hour $h$, day $d$, and location $l$ respectively.

The average daily relative humidity $A d R H$ is obtained by applying the Magnus approximation formula [33]:

$$
A d R H_{l}=100 e^{\frac{4283.58\left(A d D^{2} D_{l}-A d T_{l}\right)}{\left(243.04+A d T D_{l}\right)\left(243.04+A d T_{l}\right)}}
$$

The magnitude of wind vector $A d W$ is calculated as

$$
A d W_{l}=\frac{1}{D H} \sum_{d=1}^{D} \sum_{h=1}^{H} \sqrt{u_{h d l}^{2}+v_{h d l}^{2}}
$$

where $u_{h d l}$ and $v_{h d l}$ are the west-east and south-north components of the wind at hour $h$, day $d$, and location $l$ respectively.

For each species, we obtained a $1 \times n$ vector at a last day $D$, where $n$ is the number of areas considered.

\subsection{Epidemiological Data}

Given the open data policy of the Italian Government, for Italy it was possible to obtain the daily data of the SARS-CoV-2 infected people per province and region. The demographic data were collected from the site http://www.comuni-italiani.it/provincep.html. The Italian SARS-CoV-2 case data are retrieved from https://github.com/pcm-dpc/COVID-19 in the form of daily, comma-separated files. For each day, we collected a set of $m \times n$ matrices, where $m$ is the number of days and $n$ is the number of the provinces or regions.

In the case of the other three European countries, France, Germany and Spain (FGS), the data were not centralized or specified at the time of the analysis and were manually imported without the possibility of being separated into subgroups of cases. The total number of cases for 18 French, 16 German and 19 Spanish regions were obtained from https://www.statista.com/ referring to the 25th of March. Four French and one Spanish regions were removed from our analysis, as they were located outside the topographic European domain.

\subsection{Statistical Analysis}

The pairwise Spearman Correlation Coefficients were computed for all the atmospheric factors. Conditioning plots were then applied to graphically assess the dependence of the number of infected cases per million of one factor conditioned to different levels of another factor.

The infection data used per province are the total number of patients on 25th of March and 15th of April, whereas for the regions we used the number of total, not hospitalized and hospitalized cases. We calculated $A d M_{l}$, where $l=\mathrm{PM}_{2.5}, \mathrm{PM}_{10}, \mathrm{O}_{3}$ and $\mathrm{NH}_{3}$ considering $D=27$ (endpoint 19th March and 9th April).

\subsection{Binary Classifier}

A binary classifier based on an artificial neural network (ANN) was implemented to test the capacity of the atmospheric variables to predict the epidemic escalation of the number of positive cases per million on the basis of a combination of $A d M_{l}$ where $l=\mathrm{PM}_{2.5}, \mathrm{PM}_{10}, \mathrm{NH}_{3}$ and $\mathrm{O}_{3}$. All the $A d M_{l}$ values were pre-scaled to be homogeneous. We defined epidemic escalation, at the testing time (25th of March and 15th of April), as incidences where the number of cases per million (at the time of the 
present analysis) is more than one standard deviation $\left(\sigma_{1}=480, \sigma_{2}=1002\right)$, above the mean $\left(\mu_{1}=543\right.$, $\mu_{2}=1551$ ) of the number of cases per million in the first twenty nations listed in the coronavirus survey https://www.worldometers.info/coronavirus/ and https://github.com/owid/covid-19-data/tree/master/ public/data. We call this value escalation threshold $\left(T_{e 1}=1023\right.$ cases per million and $T_{e 2}=2553$ cases per million at 25th of March and 15th of April, respectively). The binary classifier was developed using a feed-forward ANN with $n$ inputs, one output and $\mathrm{h}$ hidden components using the neuralnet $\mathrm{R}$ package. The number of inputs $n$ depends on the number of regressors used as input, whereas the number of the hidden components was selected during the training phase with the Italian province datasets. The dimensionality of the input parameters was finally reduced to the usage of two variables, $\mathrm{PM}_{2.5}$ and $\mathrm{O}_{3}$.

To validate the models, we selected a Monte Carlo cross-validation strategy. The observed number of data was split randomly multiple times $(n=100)$ into two datasets, the training $(R)$ and the test $(T)$, containing 75 and 32 provinces, respectively. For each combination of regressors, we varied the number of hidden layers from 3 to 15 . We defined as true negative (TN) all the provinces in $T$ that have a number of cases that is lower than the selected threshold. The true positives (TP) are provinces where the number of cases is higher than the threshold. The false positives $(F P)$ are all the provinces predicted with epidemic escalation but where the number of cases is lower than the threshold. The false negatives $(F N)$ are all the provinces predicted without epidemic escalation but where the number of cases is higher than the thresholds. The random assignment to $R$ or $T$ was performed 100 times for each combination of the parameters. A null predictor was implemented with a random swapping of the number of cases. To measure the performances of the binary classifier and the null predictor, we used four indices: sensitivity $\left(S E=\frac{T P}{T P+F N}\right)$, specificity $\left(S p=\frac{T N}{T N+F P}\right)$, accuracy $\left(A C C=\frac{T P+T N}{T P+F N+T N+F P}\right)$, and precision $\left(P R C=\frac{T P}{T P+F P}\right)$ for $\mathrm{PM}_{2.5}, \mathrm{PM}_{10}, \mathrm{NH}_{3}, \mathrm{O}_{3}$, and the combinations of the four factors. The best model and threshold that maximize the sum of all four indices on an average of 100 training-testing phases were selected. To associate the prediction results to the country maps we recorded for each administrative area, the number of times that the conditions in that province were predicted escalated when the province was assigned to the test dataset $(T)$.

\subsection{Classifier Evaluation}

To evaluate the capacity of the classifier we collected the total number of SARS-CoV-2 cases for three European nations, France, Germany and Spain, from 25th of March. The atmospheric factors $\mathrm{PM}_{2.5}$ and $\mathrm{O}_{3}$ were extracted in the same way as described in the study setting and data section. The data were then scaled following the same procedure, and the conditioned factors were used to feed the classifier to measure the performances on completely unseen data. The expected number of infected cases in the total of 107 Italian provinces were predicted for the months of March (Spring), June (Summer), September (Autumn) and December (Winter) using the real measured values for $\mathrm{PM}_{2.5}$ and $\mathrm{O}_{3}$ atmospheric factors from 2018 seasonal datasets.

\subsection{Informal Boolean Approximation}

The results of the predictions and the previous results were condensed into a simplified Boolean model. The explaining continuous factors, $\mathrm{PM}_{2.5}(V(p))$, and ozone $(V(o))$, where $p$ and $o$ are concentrations, are seen as boolean variables that refer to two states, present $\left(V\left(p>T_{p}\right), V\left(o>T_{o}\right)\right.$ or not present, depending on the unknown thresholds $\left(T_{p}, T_{o}\right)$. As the atmospheric factors considered are limited source that influences the severity of infection, all the hidden factors are summarized by a single hidden variable $V(u)$ with unknown characteristics. The effect of the combination of the three variables on the epidemic has two states, escalating and non-escalating, on the basis of the described epidemic escalation threshold $T_{e}$. This model is qualitative, and the activation thresholds $T_{p, o}$ are not explicitly calculated. The observation that the modality of the interactions among factors derived from the regression step is not known, justified the usage of an ANN as a general approximator. 


\subsection{Administrative Maps}

The administrative maps for Italy, France, Germany and Spain were obtained from GADM service (https://gadm.org/about.html) version 3.6. The four country maps are then coloured accordingly with the number of reported cases until 25th of March and the corresponding ANN prediction. The AdM values for $\mathrm{PM}_{2.5}$ and $\mathrm{O}_{3}$ are mapped for Italy.

\section{Results}

The concentration of four air pollutants and five atmospheric variables in 107 Italian and 47 FGS areas were sampled over a period of 27 days from $00 \mathrm{AM}$ on the 10th of February until the $00 \mathrm{AM}$ of the 10th of April. The average population of an Italian province is 572,646 inhabitants, with an average number of cases per million of 1226 at the time of the study. On the same day, the average population and number of cases per million in the FGS regions was 4,241,214 and 1097, respectively. In the first 20 countries, ranked by the total number of cases at the day of the study, the average number of cases per million was 480 (25th of March) and 1551 (15th of April).

To measure the strength of association between all the variables in the provinces, we used the Spearman coefficients (SCs) (Supplementary Table S1). All the $A d M_{P M 2.5}, A d M_{P M 10}$, and $A d M_{N_{3}}$ values were nearly identical with the respective $A d V_{l}$ values $(r>0.99)$, suggesting that the two indexes are redundant. The $A d M_{O_{3}}$ and $A d V_{O_{3}}$ values were correlated with slightly lower SC $(r=0.91)$. Correlation matrix for $\mathrm{PM}_{2.5}, \mathrm{PM}_{10}$ and $\mathrm{NH}_{3}$ shows a strong positive inter-variables correlation $(r>0.7)$. The number of SARS-CoV-2 cases per million (Cas, Table 1) shows a significant positive correlation with three of the four pollutant variables $\mathrm{PM}_{2.5}, \mathrm{PM}_{10}$, and $\mathrm{NH}_{3}(0.58 \leq r \leq 0.68) . \mathrm{O}_{3}$, instead, shows a good negative correlation with Cas $(r=-0.44)$. All the atmospheric variables, except the surface pressure, are mildly inversely associated with the number of cases $(-0.327<r<0.253)$. We introduced the density population (inhabitants $/ \mathrm{km}^{2}$ ) of the province (PD) to assess a correlation between the number of inhabitants and atmospheric pollution (Table 1). A limited correlation was found between the PD, $\mathrm{PM}_{2.5}$ and $\mathrm{PM}_{10}(0.35426=<r<=0.3771)$. Moreover, no correlation was found among the density and $\mathrm{NH}_{3}$. For $\mathrm{O}_{3}$, a modest negative correlation with $\mathrm{PD}(r=-0.244)$ was detected. For all the atmospheric variables, no association was found. The association between the pollutant and atmospheric variables is shown in Table 2. Ozone is positively associated with all the atmospheric variables except for the pressure $\mathrm{P}$. Conversely, $\mathrm{PM}_{2.5}, \mathrm{PM}_{10}$, and $\mathrm{NH}_{3}$ are negatively correlated with all the atmospheric variables except for a limited positive association with atmospheric pressure. Overall, all tested pollutant variables display an extremely high degree of intra-variable correlation, allowing us to reduce the dimensionality of the variable space. High inter-variable correlation among $\mathrm{PM}_{2.5}, \mathrm{PM}_{10}$, and $\mathrm{NH}_{3}$ makes these variables redundant.

Table 1. The correlation vectors between population density (PD), $\mathrm{PM}_{2.5}, \mathrm{PM}_{10}, \mathrm{NH}_{3}, \mathrm{O}_{3}$, dew-point temperature (TD), temperature $(\mathrm{T})$, relative humidity $(\mathrm{RH})$, wind $(\mathrm{W})$, pressure $(\mathrm{P})$ and number of SARS-CoV-2 cases in Italian provinces (Cas).

\begin{tabular}{ccc}
\hline & PD & Cas \\
\hline $\mathrm{PD}$ & 1.000 & 0.034 \\
$\mathrm{PM}_{10}$ & 0.377 & 0.586 \\
$\mathrm{PM}_{2.5}$ & 0.354 & 0.597 \\
$\mathrm{NH}_{3} \max$ & 0.084 & 0.693 \\
$\mathrm{O}_{3} \max$ & -0.244 & -0.444 \\
$\mathrm{TD}$ & 0.045 & -0.327 \\
$\mathrm{~T}$ & 0.094 & -0.284 \\
$\mathrm{RH}$ & -0.108 & -0.253 \\
WIND & 0.006 & -0.327 \\
$\mathrm{P}$ & 0.188 & -0.025 \\
\hline
\end{tabular}


Table 2. The correlation matrix among the pollutant variables $\left(\mathrm{PM}_{2.5}, \mathrm{PM}_{10}, \mathrm{NH}_{3}, \mathrm{O}_{3}\right)$ and the atmospheric variables (TD, T, RH, and $\mathrm{P}$ ) in the Italian provinces.

\begin{tabular}{cccccc}
\hline & TD & T & RH & WIND & P \\
\hline $\mathrm{PM}_{10}$ & -0.209 & -0.136 & -0.282 & -0.441 & 0.269 \\
$\mathrm{PM}_{2.5}$ & -0.300 & -0.221 & -0.336 & -0.520 & 0.192 \\
$\mathrm{NH}_{3}$ & -0.227 & -0.168 & -0.253 & -0.377 & 0.164 \\
$\mathrm{O}_{3}$ & 0.471 & 0.351 & 0.502 & 0.439 & 0.025 \\
\hline
\end{tabular}

To visually assess geographical distribution of $\mathrm{PM}_{2.5}, \mathrm{PM}_{10}$ and $\mathrm{O}_{3}$ concentration with respect to the number of SARS-CoV-2 cases, we generated scatter plot diagrams of three Italian macroregions: north, central and south (Figure 1A-C). While in the south of Italy (green dots, lat < 41.5), PM occupy the left part of the plot, remaining under $30 \mu \mathrm{g} / \mathrm{m}^{3}\left(\mathrm{PM}_{2.5}\right)$ and $40 \mu \mathrm{g} / \mathrm{m}^{3}\left(\mathrm{PM}_{10}\right)$ (Figure $\left.1 \mathrm{~A}, \mathrm{~B}\right)$, northern provinces show a more extended range of values, with the highest number of cases. The distribution of $\mathrm{O}_{3}$ (Figure $1 \mathrm{C}$ ), is instead more uniform between regions, in a range of 0.03 to $0.05 \mathrm{ppm}$. When we combined the data from Italian provinces and FGS regions, the distribution of the PM (Figure 1D,E) in the FGS regions was clearly lower, similar to the value observed in the south of Italy $\left(<30 \mu \mathrm{g} / \mathrm{m}^{3}\right)$. The distribution of the ozone concentration is narrower in the FGS regions, with a shorter tail at the lower concentrations (Figure 1F).

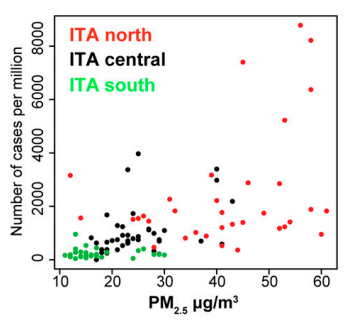

B

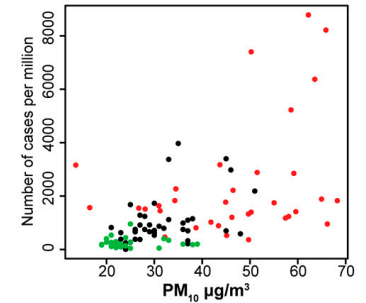

C

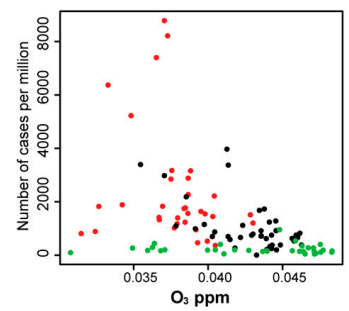

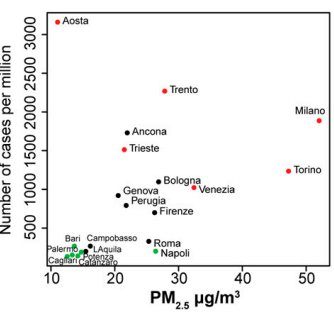
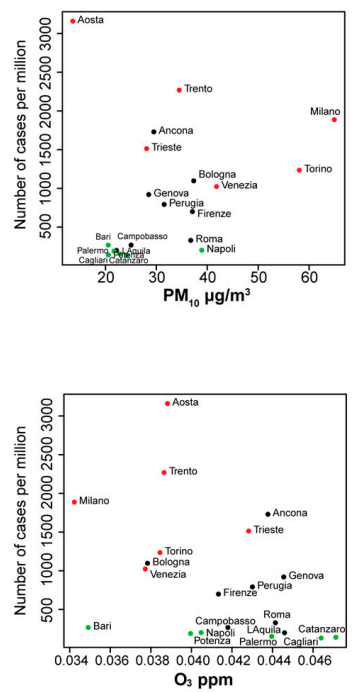

D

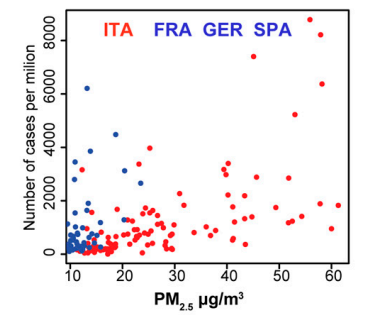

E

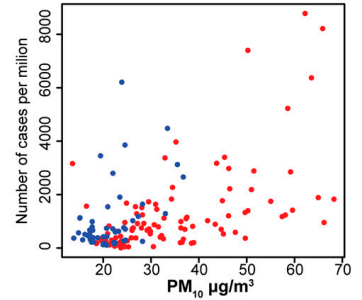

F

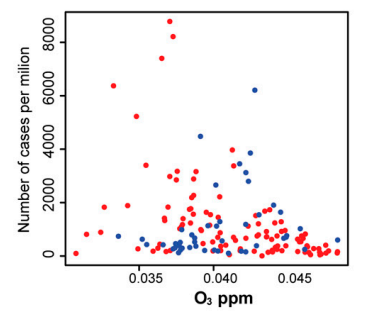

Figure 1. Correlation between SARS-CoV-2 cases in 107 Italian provinces using $\mathrm{PM}_{2.5}, \mathrm{PM}_{10}$ and $\mathrm{O}_{3}$. The scatterplots display the values of three atmospheric factors and the number of cases per million in 107 provinces (left panels) and selected provinces with regional capitals (middle panels). (A) $\mathrm{PM}_{2.5}$; (B) $\mathrm{PM}_{10}$; (C) $\mathrm{O}_{3}$. Different colors represent Italian provinces at different latitudes. Red dots: provinces with a latitude higher than $44.84 \mathrm{~N}$; black dots: provinces with a latitude comprised between $41.50 \mathrm{~N}$ and $44.86 \mathrm{~N}$; green dots: provinces with a latitude lower than $41.50 \mathrm{~N}$. (D-F) The scatterplots display the concentration of $\mathrm{PM}_{2.5}, \mathrm{PM}_{10}$, and $\mathrm{O}_{3}$. Red dots represent Italian provinces, blue dots FGS regions. 
Next, to account for relations that may be obscured by the effects of other variables, we generated a collection of conditional plots (Figure 2 and Supplementary Figure S1) [34]. We analyzed $\mathrm{PM}_{2.5}$ (Figure 2A) and the $\mathrm{O}_{3}$ (Figure 2B,C) as the explanatory variables for the number of cases and $\mathrm{PM}_{2.5}$ (Figure 2A,C) and $\mathrm{O}_{3}$ (Figure 2B) as conditional values. When the variables are self-conditioning (Figure 2A,B), the number of SARS-CoV-2 cases per million depends on $\mathrm{PM}_{2.5}$ and $\mathrm{O}_{3}$ on an apparent opposite ways; $\mathrm{PM}_{2.5}$ at concentrations higher than $30 \mu \mathrm{g} / \mathrm{m}^{3}$ (fifth and sixth scatter plot in Figure 2A) and $\mathrm{O}_{3}$ at concentrations lower than $0.04 \mathrm{ppm}$ (first and second scatter plot in Figure 2B). The number of cases per million starts to be dependent on $\mathrm{O}_{3}$ concentration only when the $\mathrm{PM}_{2.5}$ are higher than about $30 \mu \mathrm{g} / \mathrm{m}^{3}$ (fifth and sixth scatter plot in Figure 2C). In summary, conditional plots show that the number of cases per million appears to be non-linearly linked with the $\mathrm{O}_{3}$ data due to a threshold effect on the ozone linked to the $\mathrm{PM}_{2.5}$ concentration. The same threshold effect seems to hold true for the other two analyzed variables, $\mathrm{PM}_{10}$ and $\mathrm{NH}_{3}$ (Supplementary Figure S1).

The ANN classifier with three hidden neurons (Supplementary Figure S2A) returned the highest score in SE, SP, ACC and PRC (Figure 3A and Supplementary Figure S2D), so this topology was selected to classify the datasets.

A
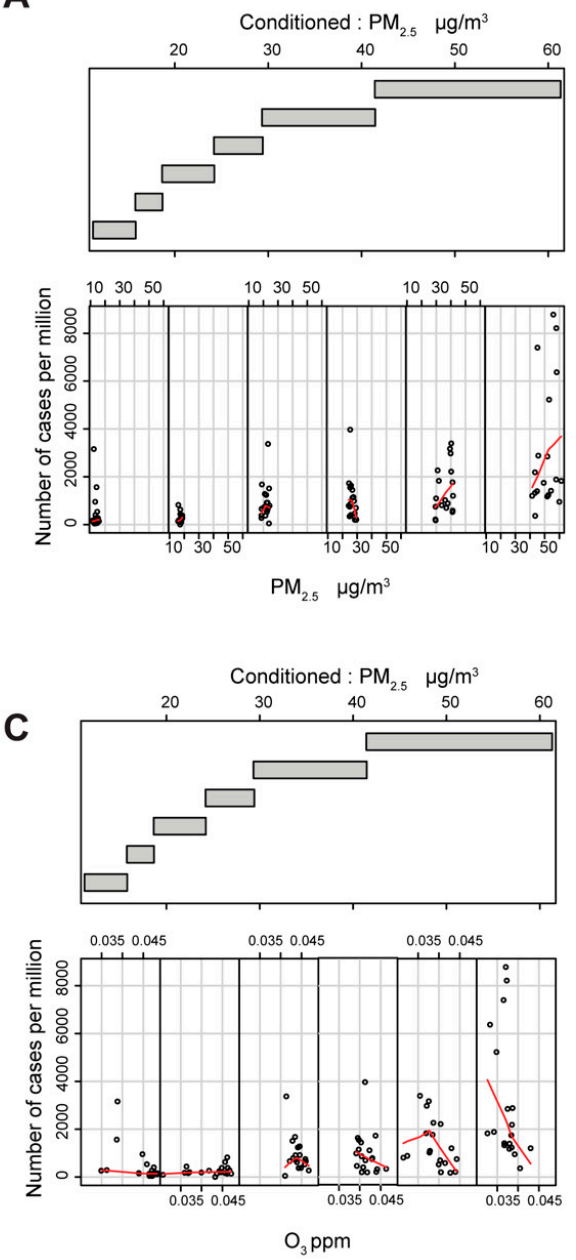

B

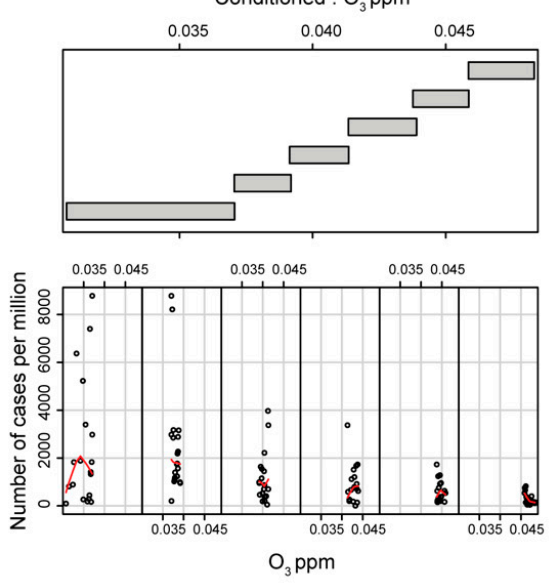

Figure 2. Evaluation of the cross-influence between $\mathrm{PM}_{2.5}$ and $\mathrm{O}_{3}$. Lower panel: the scatter plots between the selected factor and the number of cases per million. The LOESS curve is computed in each scatterplot and shown in red. Each plot is restricted to show datapoints that belong to the provinces that fall in the corresponding range of the conditioning factor. Upper plot: the range of the values that define each level of conditioning. The overlap among the levels is 0.1. (A) the scatterplot of $\mathrm{PM}_{2.5}$ conditioned to $\mathrm{PM}_{2.5} ;$ (B) the scatterplot of $\mathrm{O}_{3}$ conditioned to $\mathrm{O}_{3} ;(\mathbf{C})$ the scatterplot of $\mathrm{O}_{3}$ conditioned to $\mathrm{PM}_{2.5}$. 
A

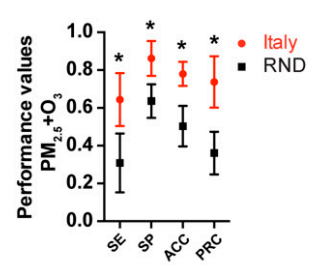

C

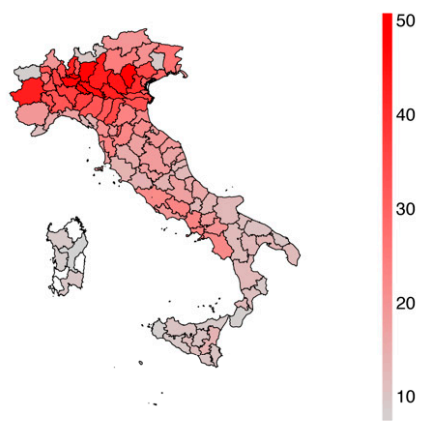

B

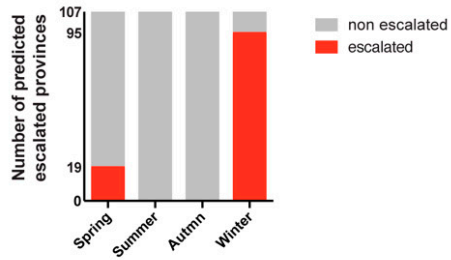

D

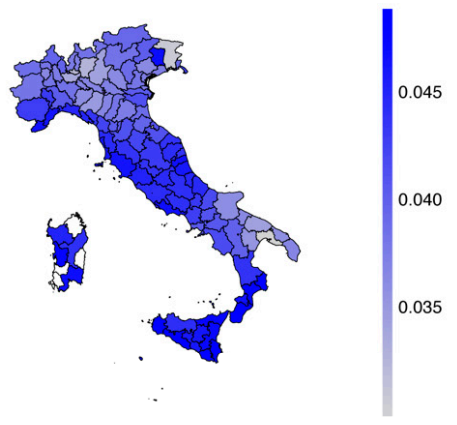

$\mathbf{F}$

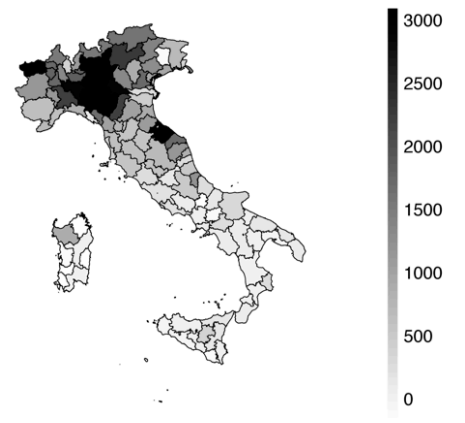

Figure 3. ANN performance assessment. (A) Performance values of the ANN on the 107 Italian provinces (left) and FGS (right) data. SE sensitivity, SP specificity, ACC accuracy, PRC precision. The dots represent the ANN average performance based on 100 Monte Carlo cross-validations. Bars represent the standard deviation. Red dots Italian provinces, blue dots FGS regions and black dots random dataset. (B) The histogram represents the number of the escalated Italian provinces (107) considering the $\mathrm{PM}_{2.5}$ and $\mathrm{O}_{3}$ concentrations in four months, March, June, September, and December, representative of the four seasons: Spring, Summer, Autumn, and Winter. Red bars, number of escalated provinces, grey bars, remaining non escalated provinces. Statistical analysis were performed using multiple $t$ test corrected with the Sidak-Boneferroni method for multiple comparisons $(p<0.001)$. Black asterisk indicates that the classifier performs better than the null classifier. Red asterisk indicates that the classifier performs worse than the null classifier. (C-F) The spatial administrative maps representing $\mathrm{PM}_{2.5}\left(\mu \mathrm{g} / \mathrm{m}^{3}\right.$, red), $\mathrm{O}_{3}$ (ppm, blue), prediction (number of positive predictions, orange) and actual reported cases (number of cases per million, black) for the Italian provinces. (E) The color intensity on the map represents the number of times that provinces in the test dataset were positive for the outbreak in one hundred Monte Carlo cross-validations. (F) The number of actual reported cases was limited to 3000 per million to increase the dynamic range of the map.

The prediction for the Italian provinces using $\mathrm{PM}_{2.5}, \mathrm{O}_{3}$ and both variables are summarized in Supplementary Figure S2D and Figure 3A, left panel. The classifier with both $\mathrm{PM}_{2.5}$ and $\mathrm{O}_{3}$ has sensitivity, specificity, accuracy, and precision that are highly significant with respect to the null predictor. The usage of only $\mathrm{PM}_{2.5}$ or $\mathrm{O}_{3}$ is still significant but with a decreased capacity to predict 
the escalated provinces (Supplementary Figure S2D). To visually represent the variables used and the prediction results of the classifier, we produced spatial maps for $\mathrm{PM}_{2.5}, \mathrm{O}_{3}$, the prediction of the conditions for SARS-CoV-2 escalation and the actual number of SARS-CoV-2 cases (Figure 3C-F).

For the FGS data, the results show a lower capacity of the combination of $\mathrm{PM}_{2.5}$ and $\mathrm{O}_{3}$ in classifying performances (Supplementary Figure S2E). When only $\mathrm{PM}_{2.5}$ was used (Figure 3A, right panel), the predictor behaved better than the null model for specificity, accuracy and precision. The classification efficiency of $\mathrm{O}_{3}$ alone was sub-performing for all the four performance indexes.

Next, we tested the classifier seasonal predictive behavior, taking the $A v M$ from the 107 Italian provinces, extracted from the seasonal recordings of March (Spring), June (Summer), September (Autumn), and December (Winter) 2018 (Figure 3B). Zero outbreaks were predicted in June and September (Summer and Autumn), whereas 19/107 outbreaks were found in March (Spring) and 95/107 in December (Winter).

Taken together, the classification results show that the low concentration of the particulate is a reliable predictor for the absence of epidemic escalation. At medium-high values, the model predicts the epidemic escalation in combination with low (high epidemic escalation likelihood), or high (low epidemic escalation likelihood) concentration of ozone well. This observation makes the ozone a possible predictor only if the quantity of particulate is significantly high. For all the conditions where the $\mathrm{PM}_{2.5}$ is low, the unknown factors explained by unknown variables $\left(V_{U}\right)$ are prevailing in explaining the epidemic escalation.

Finally, we explore the hypothesis that atmospheric conditions that favor the formation of $\mathrm{PM}$ and possibly viral micro droplets differentially influence the severity of SARS-CoV-2 infection. By separating hospitalized and not hospitalized cases in the 21 Italian regions, we found a significant positive correlation $\left(R^{2}=0.4891, p=0.0004\right)$ between the particulate matter quantities and the number of hospitalized patients (Figure 4A), whereas for infected but not hospitalized population, this was not the case $\left(R^{2}=0.01154, p=0.6430\right)$. Ozone instead showed a significant negative correlation with the hospitalized population $\left(R^{2}=0.2355, p=0.0257\right)$ and a not significant negative correlation $\left(R^{2}=0.1590\right.$, $p=0.0734$ ) with the not hospitalized population (Figure 4B).

A

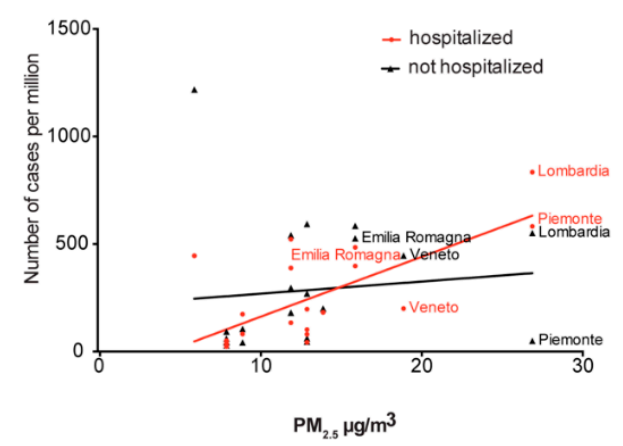

B

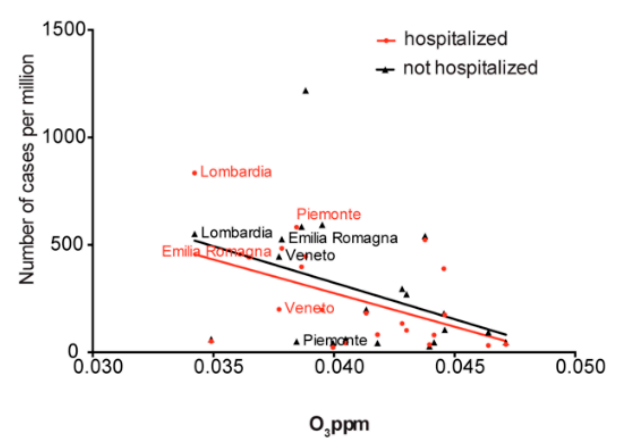

Figure 4. Correlation between hospitalized and not hospitalized cases in 21 Italian regions using $\mathrm{PM}_{2.5}$ and $\mathrm{O}_{3}$. (A) Scatter plot of the hospitalized (red points) and not hospitalized (black points) versus the concentration of $\mathrm{PM}_{2.5}$ in 21 Italian regions. Red line, positive correlation $\left(R^{2}=0.4891, p=0.0004\right)$; black line, no significant correlation $\left(R^{2}=0.01154, p=0.6430\right)$. The labels represent the four regions with the highest number of cases per million. (B) Scatter plot of the hospitalized (red points) and not hospitalized (black points) versus the concentration of ozone in 21 Italian regions. Red line, negative correlation $\left(R^{2}=0.2355, p=0.0257\right)$; black line negative correlation $\left(R^{2}=0.1590, p=0.0734\right)$. The labels represent the four regions with the highest number of cases per million.

To continuously monitor the capacity of our framework to predict the spread of the SARS-CoV-2 in the 154 areas, we regularly update the $\mathrm{PM}_{2.5}$ and $\mathrm{O}_{3}$ data and perform a real-time forecasting of the infection. The result of this analysis is provided in https://github.com/COVID19Upcome/Europe. 


\section{Discussion}

In the present study, we have built a predictive model for the SARS-CoV-2 viral outbreak as a function of atmospheric pollutants, $\mathrm{PM}_{2.5}, \mathrm{PM}_{10}, \mathrm{NH}_{3}$ and $\mathrm{O}_{3}$. Our hypothesis is based on the correlation between viral outbreak and physicochemical factors that contribute to the enrichment of the atmospheric particulate. This was supported by the analysis of five additional climatic parameters, T, TD, W, HR and P, out of which the first four were found to be associated with the number of SARS-CoV-2 cases (Table 1), in line with what was reported recently [35].

Based on the Spearman coefficients and the conditional plots (Supplementary Table S1, Figure 2 and Supplementary Figure S1), we chose to favor the use of the average daily maximum values of $\mathrm{PM}_{2.5}$ and $\mathrm{O}_{3}$ to build the ANN classifier for prediction of SARS-CoV-2 outbreaks. The ANN model with two input variables, $\mathrm{PM}_{2.5}$ and $\mathrm{O}_{3}$, and three hidden layers, was trained with 107 Italian provinces, which resulted in a significant predictive ability for all four considered performance values (Figure $3 \mathrm{~A}$ and Supplementary Figure S2D). The same model, however, tested on FGS regions, showed a limited capacity to classify the epidemic escalation in those regions. A more in-depth analysis taking into account predictors with only a single atmospheric input variable resulted in the amelioration of the predictive capacity with only $\mathrm{PM}_{2.5}$ in the FGS regions. However, systematic underperformance with respect to the null model was observed when only the $\mathrm{O}_{3}$ parameter was used. These results allowed us to build an informal logic approximation that accounts also for the unknown causative variables (Supplementary Figure $\mathrm{S} 2 \mathrm{~B}$ ). When the $\mathrm{PM}_{2.5}$ concentration is low, the capacity of the $\mathrm{PM}_{2.5}$ model to catch non-escalating regions (true negatives) is high, as few of them show outbreaks $(S P>0.9)$. We thus introduced the unknown causative variables to explain the rising case numbers when $\mathrm{PM}_{2.5}$ concentration is low (Supplementary Figure S2B, left branch of the model). However, when the $\mathrm{PM}_{2.5}$ concentration is high, the $\mathrm{O}_{3}$ is contributing positively to the capacity of the model in predicting the outbreaks (Figure 3A, SE $=0.64$ ). This implies the existence of a variable threshold, in this case $\mathrm{PM}_{2.5}$ concentration, that acts on the $\mathrm{O}_{3}$ predictive capacity. This threshold is exemplified in the right branch of the model in Supplementary Figure S2B. In fact, the predictions in the FGS regions, where the outbreak conditions at the time of the analysis do not visually match the course of the infection, might be due to low values of $\mathrm{PM}_{2.5}$ (Figure 1D and Supplementary Figure S3). On the other hand, the predicted outbreak areas in Italy clearly resemble the actual distribution of the infected population (Figures $1 \mathrm{~A}$ and $3 \mathrm{C}-\mathrm{F}$ ).

SARS-CoV-2 is an emerging pathogen, and our study is therefore subjected to possible limitations, primarily access to data and time constraints. Our model was validated based on publicly available data, different sampling policies and unknown fractions of untested/asymptomatic infected individuals, all of which could impact the accuracy of the collected datasets. Moreover, data access to the broader set of atmospheric factors with more powerful modeling strategies could be applied to establish explicit causal relation with the infection dynamic. Finally, the findings of our study should be seen in light of the ongoing new pandemic, which gives our analysis a short time window. However, verifying the classifier by using the two upper and lower margins ( 2 and 14 days lag), we observed slightly lowered predictive capability (Supplementary Table S2), suggesting that the 6 days lag used throughout the analysis is a good compromise for the incubation period. In the same line, by shortening the averaging widow for pollutants $(D=7, D=14)$, we also probed ANN performance and observed that by increasing the exposure time, the prediction performance was higher (Supplementary Table S2). On this point, a comprehensive temporal synchronization based on epidemiological parameters, combined with the exploration of new additional climatic parameters and averaging schema, could improve the modelling of the airborne virus transmission dynamics.

Nevertheless, our data support the concept that the atmospheric conditions can both (1) promote the formation of persisting forms of airborne droplets charged with SARS-CoV-2 ( $\left.\mathrm{PM}_{2.5}\right)$, and (2) reduce the activity of the virus $\left(\mathrm{O}_{3}\right)$. We thus hypothesized that the increase in the concentration of $\mathrm{PM}_{2.5}$ may reflect the rise of infective droplets with a diameter inferior to 5 microns. We speculate that 
the fast evaporation of droplets emitted by talking or sneezing increases the sustained circulation of micro-droplets that carry a higher viral load, particularly in closed spaces.

In line with this, it has been shown for an airborne influenza virus that $49 \%$ of the viral particles are present in the droplets with a dimension between 1 and $4 \mu \mathrm{m}$. In general, droplets with a dimension bigger than $50 \mu \mathrm{m}$ fall immediately to the ground, whereas particles with a dimension of $5 \mu \mathrm{m}$ take more than an hour to reach the ground from a height of $3 \mathrm{~m}$ [36]. Moreover, particles with an aerodynamic diameter smaller than $2 \mu \mathrm{m}$ remain suspended in the air for hours or days and are more able to reach the alveolar regions in the lungs [11].

The droplet size can be modulated by the difference in vapor pressure, reducing it in a few seconds, at a rate of $5 \mu \mathrm{m} / \mathrm{s}$ [37]. Moreover, droplets small enough to penetrate to the lower respiratory tract can lead to an adverse disease outcome [38-40]. These observations are remarkably significant as they show that (1) the distribution of the dimension of the droplets changes immediately so that the diameter at the emission source (infected individual) is consistently bigger than the diameter at the destination (susceptible individual), and (2) the viral concentration in the droplet (viral particles/ $\mu \mathrm{L}$ ) increases, as the volume decreases quadratically with respect to the radius. This evidence suggests that in unfavorable ambiental conditions, monitored by $\mathrm{PM}_{2.5}$ formation, the amount of persistent droplets with large viral load reflects a significant increase in the hospitalized cases (Figure 4A). This supports the findings that face mask usage can be more beneficial in avoiding the spreading of the virus from an infected individual than to block the viral particles at the susceptible (healthy) individual [41]. With this regard, our findings are in agreement with studies focusing on the airborne transmission of SARS-CoV-2 that were published while our manuscript was in preparation. In particular, the spreading of the virus via nuclei small enough to remain suspended for prolonged periods of time is considered to be a likely mode of transmission of SARS-CoV-2 [42]. Furthermore, SARS-CoV-2 diffusion has been linked to the certain atmospheric conditions that stabilize aerosols, such as low temperature and low absolute humidity [35]. Possibly the two most coherent findings that support our hypothesis that PM can be used as an early direct or indirect signal of SARS-COV-2 air diffusion, and could thus protect human lives, and lower the global economic decline, have been recently reported $[43,44]$. The study by Setti et al. showed the presence of SARS-CoV-2 RNA on the particulate matter found in the focal point of the Italian epidemic. Research carried out in the U.S Harvard School of Public Health by Wu et al. found a significant association between particulate matter concentration and COVID-19 mortality rate in the U.S. Whether PM may be involved in the viral transmission only directly, or the virus can be also transmitted independently of actual association with PM 'carriers' when the conditions of atmospheric stability are favoured, remains to be assessed by further experimental studies.

Finally, the environmental factors that influence the particulate size/concentration, may be also responsible for the seasonal dynamics of the airborne infections. Our data are in agreement with this possibility (Figure 3B), however, a more detailed analysis is required to prove this causation for SARS-CoV-2 infection. To continue exploring seasonal and daily trends, the updated predictions in the 154 regions of our model with $\mathrm{PM}_{2.5}$ and $\mathrm{O}_{3}$ as input variables, can be found at https: //github.com/COVID19Upcome/Europe.

Air pollutants unambiguously pose a hazard to human health [13]. However, the underlying pathways that link air pollutants to all-cause pathophysiological conditions, respiratory and cardiovascular morbidity and mortality still remain opaque due to the complex interplay between genetic predisposition, environmental as well as social components. This also seems to hold true for the present COVID-19 pandemic, where the host response to infection ranges from mild symptoms to severe respiratory conditions with multiple organ failure [45]. It is thus conceivable that some air pollutants, specifically particulate matter, might play a role in virus spread and pathogenicity. Our analysis supports the hypothesis that the atmospheric conditions that increase the particulate matter formation, are also contributing to the severity of the SARS-CoV-2 infection. An appealing possibility that ozone might act to counteract/sterilize viral charge is to be further investigated. Finally, 
monitoring spatial-temporal variations in atmospheric particulate and $\mathrm{O}_{3}$ could be used as an aid to estimate upcoming trends for the SARS-CoV-2 transmission impact.

Supplementary Materials: The following are available online at http:/www.mdpi.com/1999-4915/12/6/588/s1.

Author Contributions: R.F. and B.L. conceived the project. R.F. designed the experiments. R.F. performed in silico experiments and bioinformatic analysis. R.F. and B.L. analyzed data. R.F., M.L., M.S. and B.L. wrote the manuscript. All authors have read and agreed to the published version of the manuscript.

Funding: This research received no external funding.

Acknowledgments: The authors thank Iva Lucic, Federico Colombo, Carlotta Penzo and the cultural association Lunebier for proofreading and helpful suggestions.

Conflicts of Interest: The authors declare that they have no conflict of interest.

\section{References}

1. Wu, A.; Peng, Y.; Huang, B.; Ding, X.; Wang, X.; Niu, P.; Meng, J.; Zhu, Z.; Zhang, Z.; Wang, J.; et al. Genome Composition and Divergence of the Novel Coronavirus (2019-nCoV) Originating in China. Cell Host Microbe 2020, 27, 325-328. [CrossRef] [PubMed]

2. Dulbecco, R.; Ginsberg, H.S. Virology; Lippincott Williams \& Wilkins: Philadelphia, PA, USA, 1988.

3. Firquet, S.; Beaujard, S.; Lobert, P.-E.; Sané, F.; Caloone, D.; Izard, D.; Hober, D. Survival of Enveloped and Non-Enveloped Viruses on Inanimate Surfaces. Microbes Environ. 2015, 30, 140-144. [CrossRef] [PubMed]

4. Van Doremalen, N.; Bushmaker, T.; Morris, D.H.; Holbrook, M.G.; Gamble, A.; Williamson, B.N.; Tamin, A.; Harcourt, J.L.; Thornburg, N.J.; Gerber, S.I.; et al. Aerosol and Surface Stability of SARS-CoV-2 as Compared with SARS-CoV-1. N. Engl. J. Med. 2020. [CrossRef] [PubMed]

5. Liu, Y.; Gayle, A.A.; Wilder-Smith, A.; Rocklöv, J. The reproductive number of COVID-19 is higher compared to SARS coronavirus. J. Travel Med. 2020, 27. [CrossRef]

6. Ghinai, I.; McPherson, T.D.; Hunter, J.C.; Kirking, H.L.; Christiansen, D.; Joshi, K.; Rubin, R.; Morales-Estrada, S.; Black, S.R.; Pacilli, M.; et al. First known person-to-person transmission of severe acute respiratory syndrome coronavirus 2 (SARS-CoV-2) in the USA. Lancet 2020, 395, 1137-1144. [CrossRef]

7. Atkinson, J.; Chartier, Y.; Pessoa-Silva, C.L.; Jensen, P.; Li, Y.; Seto, W.-H. (Eds.) Natural Ventilation for Infection Control in Health-Care Settings; World Health Organization: Geneva, Switzerland, 2013; ISBN 9789241547857.

8. Morawska, L.; Cao, J. Airborne transmission of SARS-CoV-2: The world should face the reality. Environ. Int. 2020, 139, 105730. [CrossRef]

9. Stetzenbach, L.D.; Buttner, M.P.; Cruz, P. Detection and enumeration of airborne biocontaminants. Curr. Opin. Biotechnol. 2004, 15, 170-174. [CrossRef] [PubMed]

10. Wong, G.W.K.; Leung, T.F.; Fok, T.F. Outdoor air pollution and asthma. Pediatric Pulmonol. 2004, 37, 220-222. [CrossRef] [PubMed]

11. Shaman, J.; Kohn, M. Absolute humidity modulates influenza survival, transmission, and seasonality. Proc. Natl. Acad. Sci. USA 2009, 106, 3243-3248. [CrossRef]

12. Pope, C.A.; Arden Pope, C.; Dockery, D.W. Health Effects of Fine Particulate Air Pollution: Lines that Connect. J. Air Waste Manag. Assoc. 2006, 56, 709-742. [CrossRef]

13. Pope, C.A., 3rd; Coleman, N.; Pond, Z.A.; Burnett, R.T. Fine particulate air pollution and human mortality: 25+ years of cohort studies. Environ. Res. 2020, 183, 108924. [CrossRef] [PubMed]

14. Sin, D.D.; Man, S.F.P. Chronic obstructive pulmonary disease as a risk factor for cardiovascular morbidity and mortality. Proc. Am. Thorac. Soc. 2005, 2, 8-11. [CrossRef] [PubMed]

15. Libby, P.; Ridker, P.M.; Maseri, A. Inflammation and Atherosclerosis. Circulation 2002, 105, 1135-1143. [CrossRef]

16. Li, R.; Jiang, N.; Liu, Q.; Huang, J.; Guo, X.; Liu, F.; Gao, Z. Impact of Air Pollutants on Outpatient Visits for Acute Respiratory Outcomes. Int. J. Environ. Res. Public Health 2017, 14. [CrossRef] [PubMed]

17. Strosnider, H.M.; Chang, H.H.; Darrow, L.A.; Liu, Y.; Vaidyanathan, A.; Strickland, M.J. Age-Specific Associations of Ozone and Fine Particulate Matter with Respiratory Emergency Department Visits in the United States. Am. J. Respir. Crit. Care Med. 2019, 199, 882-890. [CrossRef] [PubMed]

18. Chan, T.L.; Lippmann, M. Experimental measurements and empirical modelling of the regional deposition of inhaled particles in humans. Am. Ind. Hyg. Assoc. J. 1980, 41, 399-409. [CrossRef] [PubMed] 
19. Xing, Y.-F.; Xu, Y.-H.; Shi, M.-H.; Lian, Y.-X. The impact of PM2.5 on the human respiratory system. J. Thorac. Dis. 2016, 8, E69-E74.

20. Oberdörster, G.; Sharp, Z.; Atudorei, V.; Elder, A.; Gelein, R.; Kreyling, W.; Cox, C. Translocation of inhaled ultrafine particles to the brain. Inhal. Toxicol. 2004, 16, 437-445. [CrossRef]

21. Maher, B.A.; Ahmed, I.A.M.; Karloukovski, V.; MacLaren, D.A.; Foulds, P.G.; Allsop, D.; Mann, D.M.A.; Torres-Jardón, R.; Calderon-Garciduenas, L. Magnetite pollution nanoparticles in the human brain. Proc. Natl. Acad. Sci. USA 2016, 113, 10797-10801. [CrossRef]

22. Turner, M.C.; Jerrett, M.; Arden Pope, C.; Krewski, D.; Gapstur, S.M.; Ryan Diver, W.; Beckerman, B.S.; Marshall, J.D.; Su, J.; Crouse, D.L.; et al. Long-Term Ozone Exposure and Mortality in a Large Prospective Study. Am. J. Respir. Crit. Care Med. 2016, 193, 1134-1142. [CrossRef]

23. Al-Kindi, S.G.; Brook, R.D.; Biswal, S.; Rajagopalan, S. Environmental determinants of cardiovascular disease: Lessons learned from air pollution. Nat. Rev. Cardiol. 2020. [CrossRef] [PubMed]

24. Hiroshi, T.; Miei, S.; Kousuke, T.; Yoshiaki, M. Inactivation of Influenza Virus by Ozone Gas. H Eng. Rev. 2009, 42.

25. Wolcott, J.A.; Zee, Y.C.; Osebold, J.W. Exposure to ozone reduces influenza disease severity and alters distribution of influenza viral antigens in murine lungs. Appl. Environ. Microbiol. 1982, 44, 723-731. [CrossRef] [PubMed]

26. Jakab, G.J.; Bassett, D.J. Influenza virus infection, ozone exposure, and fibrogenesis. Am. Rev. Respir. Dis. 1990, 141, 1307-1315. [CrossRef]

27. Kutter, J.S.; Spronken, M.I.; Fraaij, P.L.; Fouchier, R.A.M.; Herfst, S. Transmission routes of respiratory viruses among humans. Curr. Opin. Virol. 2018, 28, 142-151. [CrossRef]

28. Copernicus Climate Change Service (C3S) (2017): ERA5: Fifth generation of ECMWF atmospheric reanalyses of the global climate. Copernicus Climate Change Service Climate Data Store (CDS). Available online: https://climate-adapt.eea.europa.eu/knowledge/adaptation-information/climate-services/ (accessed on 18 May 2020).

29. Schulzweida, U. CDO User Guide. 2018. CDO User Guide (Version 1.9.5). Zenodo. Available online: http://doi.org/10.5281/zenodo.1435455 (accessed on 18 May 2020).

30. Hijmans, R.J. raster: Geographic Data Analysis and Modeling. R package version 3.0-12. Available online: https://CRAN.R-project.org/package=raster (accessed on 15 April 2020).

31. Pierce, D. ncdf4: Interface to Unidata netCDF Format Data Files. R package version 1.17. Available online: https://CRAN.R-project.org/package=ncdf4 (accessed on 15 April 2020).

32. Backer, J.A.; Klinkenberg, D.; Wallinga, J. Incubation Period of 2019 Novel Coronavirus (2019-nCoV) Infections among Travellers from Wuhan, China, 20-28 January 2020. Eurosurveillance 2020, 25, 2000062. [CrossRef]

33. Alduchov, O.A.; Eskridge, R.E. Improved Magnus' form approximation of saturation vapor pressure. J. Appl. Meteorol. 1996, 35, 601-609. [CrossRef]

34. Cleveland, W.S. Coplots, Nonparametric Regression, and Conditionally Parametric Fits. Lect. Notes Monogr. Ser. 1994, 21-36. [CrossRef]

35. Ficetola, G.F.; Rubolini, D. Climate Affects Global Patterns of Covid-19 Early Outbreak Dynamics. Preprint 2020. Available online: https://www.medrxiv.org/content/10.1101/2020.03.23.20040501v2 (accessed on 20 May 2020).

36. Tellier, R. Aerosol Transmission of Influenza A Virus: A Review of New Studies. J. R. Soc. Interface R. Soc. 2009, 6 (Suppl. 6), S783-S790. [CrossRef]

37. Wang, Y.; Yang, Y.; Zou, Y.; Cao, Y.; Ren, X.; Li, Y. Evaporation and Movement of Fine Water Droplets Influenced by Initial Diameter and Relative Humidity. Aerosol Air Qual. Res. 2015, 16, 301-313. [CrossRef]

38. Morawska, L.J.G.R.; Johnson, G.R.; Ristovski, Z.D.; Hargreaves, M.; Mengersen, K.; Corbett, S.; Chao, C.Y.H.; Li, Y.; Katoshevski, D. Size Distribution and Sites of Origin of Droplets Expelled from the Human Respiratory Tract during Expiratory Activities. J. Aerosol Sci. 2009, 40, 256-269. [CrossRef]

39. Asadi, S.; Wexler, A.S.; Cappa, C.D.; Barreda, S.; Bouvier, N.M.; Ristenpart, W.D. Aerosol Emission and Superemission during Human Speech Increase with Voice Loudness. Sci. Rep. 2019, 9, 2348. [CrossRef] [PubMed]

40. Thomas, R.J. Particle Size and Pathogenicity in the Respiratory Tract. Virulence 2013, 4, 847-858. [CrossRef] [PubMed] 
41. Leung, N.H.; Chu, D.K.; Shiu, E.Y.; Chan, K.H.; McDevitt, J.J.; Hau, B.J.; Yen, H.L.; Li, Y.; Ip, D.K.; Peiris, J.M.; et al. Respiratory Virus Shedding in Exhaled Breath and Efficacy of Face Masks. Nat. Med. 2020, 1-5. [CrossRef] [PubMed]

42. Stadnytskyi, V.; Bax, C.E.; Bax, A.; Anfinrud, P. The Airborne Lifetime of Small Speech Droplets and Their Potential Importance in SARS-CoV-2 Transmission. Proc. Natl. Acad. Sci. USA 2020. [CrossRef] [PubMed]

43. Setti, L.; Passarini, F.; De Gennaro, G.; Barbieri, P.; Perrone, M.G.; Piazzalunga, A.; Borelli, M.; Palmisani, J.; Di Gilio, A.; Piscitelli, P.; et al. SARS-Cov-2 RNA Found on Particulate Matter of Bergamo in Northern Italy: First Preliminary Evidence. Preprint 2020. Available online: https://www.medrxiv.org/content/10.1101/2020. 04.15.20065995v2 (accessed on 20 May 2020).

44. Wu, L.; Nethery, R.; Sabath, B.; Braun, D.; Dominici, F. Exposure to air pollution and COVID-19 mortality in the United States: A nationwide cross-sectional study. Preprint 2020. Available online: https://www.medrxiv. org/content/10.1101/2020.04.05.20054502v2 (accessed on 20 May 2020).

45. Jin, Y.; Yang, H.; Ji, W.; Wu, W.; Chen, S.; Zhang, W.; Duan, G. Virology, Epidemiology, Pathogenesis, and Control of COVID-19. Viruses 2020, 12, 372. [CrossRef] [PubMed]

(C) 2020 by the authors. Licensee MDPI, Basel, Switzerland. This article is an open access article distributed under the terms and conditions of the Creative Commons Attribution (CC BY) license (http://creativecommons.org/licenses/by/4.0/). 